CLINICAL STUDY

\title{
Thyroglobulin in smoking mothers and their newborns at delivery suggests autoregulation of placental iodide transport overcoming thiocyanate inhibition
}

\author{
Stine L Andersen, Susanne B Nøhr ${ }^{1}$, Chun S Wu ${ }^{2}$, Jørn Olsen ${ }^{2}$, Klaus M Pedersen ${ }^{3}$ and Peter Laurberg \\ Department of Endocrinology, Aalborg University Hospital, Sdr. Skovvej 15, 9000 Aalborg, Denmark, ${ }^{1}$ Department of Postgraduate Education, Aalborg \\ University Hospital, Aalborg, Denmark, ${ }^{2}$ Section for Epidemiology, Department of Public Health, Aarhus University, Aarhus, Denmark and ${ }^{3}$ Medical \\ Department, Vejle Hospital, Vejle, Denmark \\ (Correspondence should be addressed to S L Andersen; Email: stine.a@rn.dk)
}

\begin{abstract}
Background: Placental transport of iodide is required for fetal thyroid hormone production. The sodium iodide symporter (NIS) mediates active iodide transport into the thyroid and the lactating mammary gland and is also present in placenta. NIS is competitively inhibited by thiocyanate from maternal smoking, but compensatory autoregulation of iodide transport differs between organs. The extent of autoregulation of placental iodide transport remains to be clarified.

Objective: To compare the impact of maternal smoking on thyroglobulin (Tg) levels in maternal serum at delivery and in cord serum as markers of maternal and fetal iodine deficiency.

Methods: One hundred and forty healthy, pregnant women admitted for delivery and their newborns were studied before the iodine fortification of salt in Denmark. Cotinine in urine and serum classified mothers as smokers $(n=50)$ or nonsmokers $(n=90)$. The pregnant women reported on intake of iodine-containing supplements during pregnancy and $\mathrm{Tg}$ in maternal serum at delivery and in cord serum were analyzed.

Results: In a context of mild-to-moderate iodine deficiency, smoking mothers had significantly higher serum $\mathrm{Tg}$ than nonsmoking mothers (mean Tg smokers 40.2 vs nonsmokers $24.4 \mu \mathrm{g} / \mathrm{l}, P=0.004$ ) and so had their respective newborns (cord Tg $80.2 \mathrm{vs} 52.4 \mu \mathrm{g} / \mathrm{l}, P=0.006$ ), but the ratio between $\mathrm{Tg}$ in cord serum and maternal serum was not significantly different in smokers compared with nonsmokers (smoking 2.06 vs nonsmoking 2.22, $P=0.69$ ).

Conclusion: Maternal smoking increased the degree of iodine deficiency in parallel in the mother and the fetus, as reflected by increased Tg levels. However, placental iodide transport seemed unaffected despite high thiocyanate levels, suggesting that thiocyanate-insensitive iodide transporters alternative to NIS are active or that NIS in the placenta is autoregulated to keep iodide transport unaltered.
\end{abstract}

European Journal of Endocrinology 168 723-731

\section{Introduction}

Thyroid hormones are essential for early growth and brain development, and iodine is required for thyroid hormone synthesis $(1,2)$. In the early weeks of pregnancy, the developing fetus relies on maternal thyroid hormones, but endogenous fetal thyroid hormone production contributes increasingly from the beginning of the second trimester and is dependent on placental transport of iodide from the maternal to the fetal circulation (3).

Placenta contains iodine $(4,5,6)$ and evidence suggests that a number of iodide transporters are involved in placental iodide transport. Placental tissue and cell culture studies have demonstrated that the sodium iodide symporter (NIS) is expressed in different types of placental cells $(7,8,9)$ and a functional role of
NIS in placental iodide transport has been proposed $(10,11)$. NIS is a member of the SLC5 family (SLC5A5) of sodium solute symporters and it is well known that NIS mediates the active transport of iodide into the thyroid gland (12). NIS is also expressed in the lactating mammary gland (13) mediating the active transport of iodide into breast milk (14) and in some other extrathyroidal tissues including the intestine $(15,16)$.

Another member of the SLC5 family (SLC5A6), the sodium multivitamin transporter (SMVT), has also been demonstrated in various tissues including the intestine (17) and the placenta (18). SMVT shares high sequence similarity with NIS (12) and has been demonstrated to mediate iodide transport in SMVTexpressing oocytes (19).

In addition to SLC5 family transporters, sodiumindependent iodide transporters have also been 
proposed to play a role in placental iodide transport. Pendrin is a chloride-iodide transporter expressed in the placenta and in the thyroid gland $(7,20)$.

One way to study iodide transport in humans is to observe the effect of a known iodide transport inhibitor, such as thiocyanate (21). In humans, thiocyanate $\left(\mathrm{SCN}^{-}\right)$stems from various sources, but in many populations, the most important source is tobacco smoking. Thiocyanate competitively inhibits NISmediated iodide transport in the thyroid gland; however, the reduced thyroid iodide uptake is compensated by iodide autoregulation that tends to keep thyroid iodide uptake sufficient for thyroid hormone synthesis $(12,14,22)$. On the other hand, the increased thyroid activity associated with autoregulation leads to increased serum thyroglobulin $(\mathrm{Tg})$ and increased risk of goiter in smokers $(22,23)$.

By contrast, autoregulation of NIS in the lactating mammary gland seems minimal or absent. Breast milk iodine content parallels urinary iodine excretion over a wide range of concentrations (24), and iodine supplements lead to dose-dependent increases in milk iodine content both in domestic animals (25) and in breastfeeding women (26). In accordance with this, we previously showed increased risk of iodine deficiency in breast-fed newborns of smoking mothers with no signs of NIS autoregulation in the lactating mammary gland (14).

The aim of this study was to compare the impact of maternal smoking on $\mathrm{Tg}$ levels in maternal serum at delivery and in cord serum. We studied a unique cohort of iodine-deficient pregnant women with a high frequency of smoking and their newborns. Tg in maternal serum at delivery and in cord serum was used as a marker of iodine deficiency $(27,28,29)$, and we examined the impact of thiocyanate from maternal smoking on the degree of iodine deficiency in the mother and in the fetus by comparing serum $\mathrm{Tg}$ in smoking and nonsmoking mothers and cord serum $\mathrm{Tg}$.

\section{Materials and methods}

\section{Study design and study population}

This is a cross-sectional study carried out from November 1988 to March 1990 in five different cities in Denmark $(14,24,30,31)$. As the time of study enrollment was before the mandatory Danish iodine fortification of salt introduced in the year 2000 (32), the population had in general mild (East Denmark) to moderate (West Denmark) iodine deficiency with the majority of the women under study living in an area of moderate iodine deficiency $(78.6 \%)$. A total of 152 healthy pregnant women with no history of thyroid disease, no visible goiter, and no recent exposure to excess iodine and their newborn children were studied. The pregnant women were consecutively recruited when admitted for delivery after uncomplicated pregnancy in the Departments of Obstetrics in each of the five cities (Copenhagen, $n=30$; Aarhus, $n=30$; Ringkøbing, $n=30$; Randers $n=29$; and Aalborg $n=33$ ). Six women were subsequently excluded from this study due to intermittent intake of iodine supplements, and another six women were excluded due to signs of a change in smoking status before and after delivery, thus leaving 140 pregnant women and their 140 newborn

Table 1 Characteristics of the mothers and their newborns.

\begin{tabular}{|c|c|c|c|c|c|c|c|}
\hline & \multirow[b]{2}{*}{ All $(n=140)$} & \multicolumn{3}{|c|}{ lodine supplements ${ }^{\mathrm{a}}(n=47)$} & \multicolumn{3}{|c|}{ No iodine supplements ${ }^{\mathrm{b}}(n=93)$} \\
\hline & & $\begin{array}{l}\text { Smoking } \\
(n=16)\end{array}$ & $\begin{array}{l}\text { Nonsmoking } \\
\quad(n=31)\end{array}$ & $P^{\mathrm{c}}$ & $\begin{array}{l}\text { Smoking } \\
(n=34)\end{array}$ & $\begin{array}{l}\text { Nonsmoking } \\
\quad(n=59)\end{array}$ & $P^{\mathrm{d}}$ \\
\hline \multicolumn{8}{|c|}{$\begin{array}{l}\text { Maternal age } \\
\text { (years) }\end{array}$} \\
\hline Mean & 27.3 & 27.4 & 28.2 & $0.60^{\mathrm{e}}$ & 27.6 & 26.7 & $0.32^{\mathrm{e}}$ \\
\hline S.D. & 4.5 & 4.6 & 4.7 & & 5.2 & 4.0 & \\
\hline \multicolumn{8}{|l|}{ Parity } \\
\hline Median & 1 & 1 & 1 & $0.82^{f}$ & 1 & 1 & $0.29^{f}$ \\
\hline Range & $1-5$ & $1-3$ & $1-3$ & & $1-4$ & $1-5$ & \\
\hline \multicolumn{8}{|c|}{$\begin{array}{l}\text { Gestational } \\
\text { age (weeks) }\end{array}$} \\
\hline Mean & 40.0 & 39.8 & 40.2 & $0.44^{\mathrm{e}}$ & 40.1 & 40.0 & $0.63^{\mathrm{e}}$ \\
\hline S.D. & 1.5 & 1.9 & 1.4 & & 1.6 & 1.4 & \\
\hline \multicolumn{8}{|c|}{ Birth weight (g) } \\
\hline Mean & 3520 & 3302 & 3699 & $0.01^{\mathrm{e}}$ & 3367 & 3574 & $0.04^{\mathrm{e}}$ \\
\hline S.D. & 473 & 498 & 442 & & 461 & 452 & \\
\hline
\end{tabular}

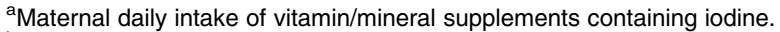

${ }^{\mathrm{b}} \mathrm{No}$ maternal daily intake of vitamin/mineral supplement containing iodine.

${ }^{\mathrm{c}}$ Statistical comparison of smokers and nonsmokers within the iodine supplement group.

dStatistical comparison of smokers and nonsmokers within the no iodine supplement group.

Independent sample $t$-test.

f Mann-Whitney $U$ test. 
children in the final study population. Informed consent was obtained from each participant and the study was approved by the Local Ethics Committee.

\section{Data collection}

When the pregnant women were admitted for delivery, detailed information was obtained on intake of iodinecontaining vitamin and mineral supplements and the women were instructed to continue their previous vitamin and mineral supplementation during the puerperal period. All women intended to breastfeed their newborn child. Blood samples $(n=138)$ were taken from the pregnant women by standard puncture of a cubital vein shortly after admission for delivery. Closure of the umbilical cord was performed within the first minute after delivery, and mixed cord blood $(n=133)$ was sampled from the placental part shortly after. After sampling, blood was centrifuged and serum was stored at $-20{ }^{\circ} \mathrm{C}$ until analyses. One cord serum sample had a limited amount of serum, which precluded some of the analyses.

On day 5 after delivery, a breast milk sample $(n=136)$ and a morning spot urine $(n=140)$ was collected from the mother and a urine sample was collected in a small self-adhesive plastic bag (Coloplast baby urine collector; Coloplast, Espergærde, Denmark) from the newborn child $(n=135)$. Urine samples were stored at $-20^{\circ} \mathrm{C}$ until analyses.

\section{Laboratory procedures}

Classification of smokers was performed by measurements of the nicotine metabolite cotinine in serum (Immulite 2000 Nicotine Metabolite Assay; analytical sensitivity $5 \mu \mathrm{g} / \mathrm{l}$, cutoff to distinguish smokers $25 \mu \mathrm{g} / \mathrm{l}$ ) and urine (double antibody RIA Diagnostic Products Cooperation; analytical sensitivity $9 \mu \mathrm{g} / \mathrm{l}$, cutoff to distinguish smokers $500 \mu \mathrm{g} / \mathrm{l}$ ), as described previously in detail (14). In participants, a clear separation of smokers $(n=50)$ and nonsmokers $(n=90)$ was obtained both when evaluated by cotinine in maternal serum when admitted for delivery (median (range) smokers $164(36->600)$ vs nonsmokers <5 $(<5-24) \mu \mathrm{g} / \mathrm{l})$ and in cord serum at delivery $(164(32->600)$ vs $<5$ $(<5-22) \mu \mathrm{g} / \mathrm{l})$ as well as in urine from the mother on day 5 postpartum (3480 (537-10 500) vs 53 (10-218) $\mu \mathrm{g} / \mathrm{l})$. Differences between smokers and nonsmokers

Table 2 Thyroid function parameters and iodine status in mothers and their newborns stratified by maternal smoking status. TSH, thyroglobulin, urinary iodine, and milk iodine were log transformed for calculation of geometric mean and $95 \% \mathrm{Cl}$.

\begin{tabular}{|c|c|c|c|c|c|c|c|c|}
\hline & \multicolumn{4}{|c|}{ Mothers } & \multicolumn{4}{|c|}{ Newborns } \\
\hline & All $(n=140)$ & $\begin{array}{c}\text { Smoking }^{\mathrm{a}} \\
(n=50)\end{array}$ & $\begin{array}{l}\text { Nonsmoking }{ }^{\mathrm{a}} \\
\quad(n=90)\end{array}$ & $P^{\mathrm{b}}$ & All $(n=140)$ & $\begin{array}{c}\text { Smoking }^{\mathrm{C}} \\
(n=50)\end{array}$ & $\begin{array}{c}\text { Nonsmo- } \\
\operatorname{king}^{\mathrm{C}}(n=90)\end{array}$ & $P^{\mathrm{d}}$ \\
\hline \multicolumn{9}{|c|}{$\mathrm{TSH}^{\mathrm{e}}(\mathrm{mU} / \mathrm{l})$} \\
\hline Mean & 2.07 & 2.05 & 2.08 & 0.85 & 8.07 & 7.21 & 8.60 & 0.12 \\
\hline $95 \% \mathrm{Cl}$ & $1.89-2.26$ & $1.77-2.37$ & $1.86-2.33$ & & $7.25-8.98$ & $6.01-8.64$ & $7.52-9.83$ & \\
\hline \multicolumn{9}{|l|}{$\mathrm{T}_{3}{ }^{\dagger}(\mathrm{nm} / \mathrm{l})$} \\
\hline Mean & 2.39 & 2.47 & 2.35 & 0.16 & 0.84 & 0.86 & 0.84 & 0.55 \\
\hline $95 \% \mathrm{Cl}$ & $2.32-2.47$ & $2.34-2.60$ & $2.25-2.45$ & & $0.80-0.88$ & $0.79-0.93$ & $0.79-0.88$ & \\
\hline \multicolumn{9}{|l|}{$\mathrm{T}_{4}{ }^{f}(\mathrm{~nm} / \mathrm{l})$} \\
\hline Mean & 177 & 175 & 178 & 0.58 & 162 & 169 & 159 & 0.054 \\
\hline $95 \% \mathrm{Cl}$ & $176-183$ & $166-184$ & $171-186$ & & $157-167$ & $160-177$ & $153-165$ & \\
\hline \multicolumn{9}{|c|}{ Free $\mathrm{T}_{4}{ }^{\mathrm{e}}(\mathrm{pmol} / \mathrm{l})$} \\
\hline Mean & 8.35 & 8.01 & 8.53 & 0.075 & 12.27 & 12.57 & 12.09 & 0.16 \\
\hline $95 \% \mathrm{Cl}$ & $8.07-8.61$ & $7.49-8.54$ & $8.22-8.84$ & & $11.94-12.60$ & $11.92-13.24$ & $11.73-12.46$ & \\
\hline \multicolumn{9}{|c|}{ Thyroglobulin $(\mu \mathrm{g} / \mathrm{l})$} \\
\hline Mean & 22.9 & 30.4 & 19.5 & 0.004 & 50.0 & 62.9 & 44.0 & 0.009 \\
\hline $95 \% \mathrm{Cl}$ & $19.7-26.5$ & $23.4-39.4$ & $16.4-23.2$ & & $43.9-57.0$ & $50.2-78.7$ & $37.6-51.4$ & \\
\hline \multicolumn{9}{|c|}{ Urinary iodine ${ }^{\mathrm{h}}(\mu \mathrm{g} / \mathrm{l})$} \\
\hline Mean & 40.6 & 40.1 & 40.8 & 0.88 & 43.5 & 33.3 & 50.4 & 0.006 \\
\hline $95 \% \mathrm{Cl}$ & $36.0-45.7$ & $34.1-47.1$ & $34.6-48.1$ & & $37.8-50.1$ & $26.8-41.5$ & $42.1-60.3$ & \\
\hline \multicolumn{9}{|c|}{ Milk iodine $(\mu \mathrm{g} / \mathrm{l})$} \\
\hline Mean & 41.4 & 26.0 & 53.8 & $<0.001$ & NA & NA & NA & \\
\hline $95 \% \mathrm{Cl}$ & $35.8-47.8$ & $20.7-32.6$ & $45.5-63.5$ & & & & & \\
\hline
\end{tabular}

NA, not applicable.

${ }^{a}$ Mothers classified as smokers or nonsmokers from cotinine in serum and urine.

${ }^{\mathrm{b}}$ Statistical comparison of smoking and nonsmoking mothers (independent sample $t$-test).

cNewborns of smoking and nonsmoking mothers.

${ }^{d}$ Statistical comparison of newborns of smoking and nonsmoking mothers (independent sample $t$-test).

e Maternal serum samples ( $n=138$; smokers $n=49$, nonsmokers $n=89)$. Cord serum samples $(n=133$; smoking mother $n=48$, nonsmoking mother $n=85)$. ${ }^{\mathrm{f}}$ Maternal serum samples ( $n=138$; smokers $n=49$, nonsmokers $\left.n=89\right)$. Cord serum samples $(n=132$; smoking mother $n=47$, nonsmoking mother $n=85)$. ${ }^{9}$ Maternal serum samples ( $n=137$; smokers $n=49$, nonsmokers $\left.n=88\right)$. Cord serum samples $(n=131$; smoking mother $n=47$, nonsmoking mother $n=84)$.

${ }^{\mathrm{h}}$ Newborn urine samples ( $n=135$; smoking mother $n=48$, nonsmoking mother $n=87$ ).

iBreast milk samples ( $n=136$; smokers $n=49$, nonsmokers $n=87$ ). 


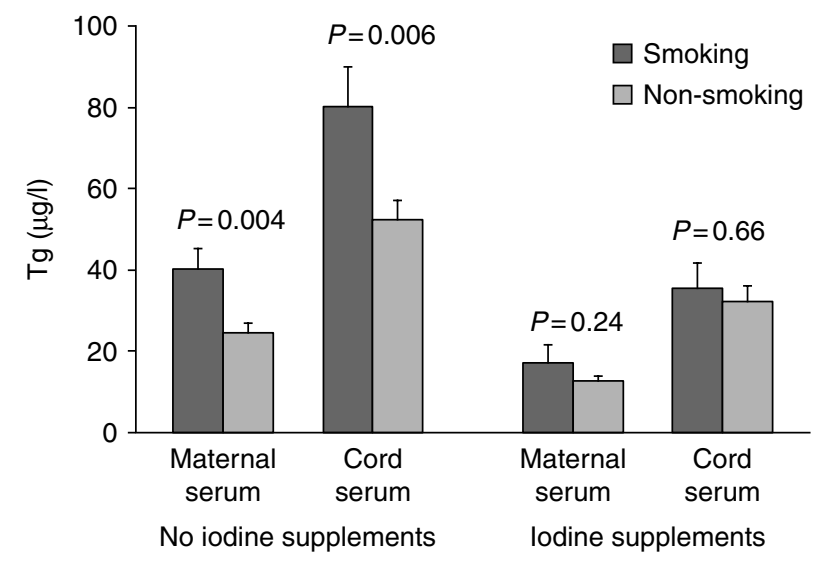

Figure 1 Thyroglobulin $(\mathrm{Tg})$ concentrations in maternal and cord serum stratified by maternal smoking status and maternal intake of iodine supplements (no maternal iodine supplements, Tg maternal serum smoking $40.2(95 \% \mathrm{Cl} 31.1-52.0)$ vs nonsmoking 24.4 (19.9-30.0) and cord serum 80.2 (63.0-102.1) vs 52.4 (43.5-63.1) $\mu \mathrm{g} / \mathrm{l}$; maternal iodine supplements, Tg maternal serum smoking $17.0(10.1-28.7)$ vs nonsmoking $12.6(9.7-16.4)$ and cord serum $35.4(24.4-51.4)$ vs $32.1(24.8-41.7) \mu \mathrm{g} / \mathrm{l})$. Log-transformed serum Tg concentrations were used for calculation of geometric mean and statistical comparison; $P$ values are results of independent sample $t$-test. Bars represent +1 S.E.M.

were substantiated by measurement of thiocyanate in maternal and cord serum by a manual method (33). Thiocyanate concentrations were considerably higher in smokers than in nonsmokers (mean (s.D.), maternal serum: smokers 84.9 (25.4) vs nonsmokers 54.7 (18.2); cord serum: smoking mother 94.6 (31.9) vs nonsmoking mother 48.3 (15.5) $\mu \mathrm{mol} / \mathrm{l})$ (14). Iodine in urine and breast milk was measured by the colorimetric method of the Sandell-Kolthoff reaction after alkaline ashing, as described previously (34).

$\mathrm{Tg}$ in maternal and cord serum was determined by an immunoluminometric assay (Behringwerke, Marburg, Germany; detection limit $<1 \mu \mathrm{g} / \mathrm{l}$ ), including recovery measurements. Tg antibodies (Tg-Ab) were measured by a very sensitive radioimmunoprecipitation assay (detection limit 20 U/l; Medical Research Council standard reference code A 65193), as described previously $(31,35)$. Tg-Ab was detectable in six maternal serum samples $(4.4 \%)$ and 14 cord serum samples $(10.6 \%)$. Because $\mathrm{Tg}-\mathrm{Ab}$ may influence $\mathrm{Tg}$ measurements (36), serum samples with $\mathrm{Tg}$-Ab values more than $200 \mathrm{U} / \mathrm{l}$ (maternal serum $n=1$, cord serum $n=2$ ) were excluded from serum $\mathrm{Tg}$ analyses. $\mathrm{Tg}-\mathrm{Ab}$ levels up to $200 \mathrm{U} / \mathrm{l}$ have previously been shown not to interfere with serum $\mathrm{Tg}$ measurements using this assay (37), and our results were consistent when limiting the analyses to samples without detectable $\mathrm{Tg}-\mathrm{Ab}$ (data not shown). Thyroid function parameters were measured in maternal and cord serum: TSH by an immunoluminometric assay (Berilux, Behringwerke), total thyroxine $\left(\mathrm{T}_{4}\right)$ and total tri-iodothyronine $\left(\mathrm{T}_{3}\right)$ by an RIA (Farmos, Turko, Finland), and free $\mathrm{T}_{4}$ by a two-step method (RIA-gnost-FT 4 , Behringwerke), as described previously (31).

\section{Statistical analyses}

Statistical analyses were performed using the Statistical Package for the Social Sciences (SPSS Statistics version 19) and Stata 11 (StataCorp., College Station, TX, USA). Concentrations of TSH, Tg, breast milk iodine, and urinary iodine showed log-normal distribution, and logarithmically transformed concentrations or ratios between concentrations were used for calculating geometric means and making statistical comparisons. We used independent sample $t$-test or Mann-Whitney $U$ test when comparing either mothers or newborns stratified by maternal smoking and/or intake of iodine supplements, whereas Tg levels in mother and child were compared using paired $t$-tests. We also evaluated serum $\mathrm{Tg}$ in multivariate linear regression models using logarithmically transformed serum $\mathrm{Tg}$ concentrations and the ratio between cord serum $\mathrm{Tg}$ and maternal serum $\mathrm{Tg}$ as dependent variables and maternal smoking, maternal intake of iodine supplements, and other variables plausibly related to serum $\mathrm{Tg}$ as potential explaining variables. We considered possible interaction between maternal smoking and maternal intake of iodine supplements by including an interaction term (smoking $\mathrm{x}$ iodine supplement intake) in the models. A 5\% level of statistical significance was chosen.

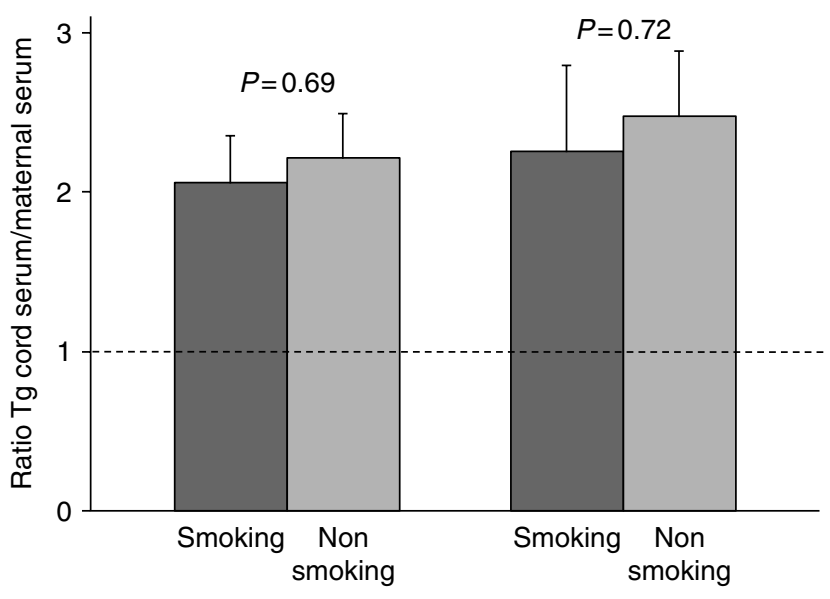

No iodine supplements

lodine supplements

Figure 2 Ratio between thyroglobulin $(\mathrm{Tg})$ in cord serum and maternal serum stratified by maternal smoking status and maternal intake of iodine supplements (no maternal iodine supplements, ratio Tg smoking $2.06(95 \% \mathrm{Cl} 1.56-2.71)$ and nonsmoking 2.22 (1.76-2.80); maternal iodine supplements, ratio Tg smoking 2.26 (1.42-3.59) and nonsmoking 2.48 (1.82-3.40)). Log-transformed ratios in individual pairs of mother and child were used for calculation of geometric mean and statistical comparison; $P$ values are results of independent sample $t$-test. Bars represent +1 S.E.M. 


\section{Results}

\section{Thyroid function and iodine status in the mothers and their newborns}

Smoking and nonsmoking mothers with and without a daily intake of iodine-containing supplements had similar age, parity, and gestational age whereas the birth weight of the newborns was lower in children born to smoking mothers (Table 1). The frequency of maternal smoking in the iodine and no iodine supplement groups was similar (no iodine supplements, $36.6 \%$ smokers; iodine supplements, $34.0 \%$ smokers) and the frequency of intake of iodine supplements in mothers was independent of maternal smoking status (smoking mothers, $32.0 \%$ iodine supplements; nonsmoking mothers, $34.4 \%$ iodine supplements). All iodine supplements contained $150 \mu \mathrm{g}$ iodine/day.

Thyroid hormone levels in maternal serum collected shortly before delivery and in cord serum collected at delivery showed a similar pattern in smoking and nonsmoking mothers as well as in their newborns (Table 2). Urinary iodine was similar in smoking and nonsmoking mothers (ratio smoking/nonsmoking $0.98,95 \%$ CI $0.76-1.26$ ), whereas in the breast-fed newborns, urinary iodine was significantly lower in newborns of smoking mothers (ratio smoking/nonsmoking 0.66, 95\% CI 0.50-0.88). In addition, breast milk iodine was reduced to approximately half in smokers (ratio smoking/nonsmoking 0.48, 95\% CI $0.37-0.64)$.

\section{Tg in maternal and cord serum}

Serum $\mathrm{Tg}$ showed different results depending on maternal intake of iodine supplements and/or maternal smoking status. Intake of iodine supplements in mothers was associated with a lower $\mathrm{Tg}$ in maternal serum (14.0 vs $29.3 \mu \mathrm{g} / \mathrm{l}$ if no iodine supplements, $P<0.001)$ and in cord serum $(31.1$ vs $61.6 \mu \mathrm{g} / \mathrm{l}$, $P<0.001$ ). Maternal smoking (Table 2) was associated with considerably higher $\mathrm{Tg}$ in maternal serum (ratio smoking/nonsmoking 1.56, 95\% CI 1.15-2.10) and in cord serum (ratio smoking/nonsmoking 1.43, 95\% CI $1.10-1.86)$.

However, the impact of maternal smoking on serum $\mathrm{Tg}$ was most striking in the no iodine supplement group when stratified by both maternal smoking and maternal intake of iodine supplements (Fig. 1). In the no iodine supplement group, smoking mothers had higher serum $\mathrm{Tg}$ (ratio smoking/nonsmoking 1.64, 95\% CI 1.18-2.29) and cord serum Tg in newborns of smoking mothers was higher (ratio smoking/nonsmoking 1.53, 95\% CI 1.14-2.06). In the group taking iodine supplements, the difference in serum $\mathrm{Tg}$ between smoking and nonsmoking mothers was statistically nonsignificant (ratio smoking/nonsmoking 1.35, 95\% CI $0.82-2.23$ ) and cord serum $\mathrm{Tg}$ was similar (ratio smoking/nonsmoking 1.10, 95\% CI 0.71-1.72).

In general, $\mathrm{Tg}$ was higher in cord serum (mean ratio cord serum/maternal serum $2.24,95 \%$ CI $1.94-2.58$, $P<0.001)$. To evaluate the degree of iodine deficiency in smoking mothers and their newborns, we compared serum $\mathrm{Tg}$ ratios, cord serum relative to maternal serum, in individual pairs of mother and child (Fig. 2). The ratios were similar in smokers and nonsmokers independent of maternal intake of iodine supplements.

The associations between serum $\mathrm{Tg}$ in mother and fetus, maternal intake of iodine supplements, and maternal smoking status were also studied in multivariate linear regression models (Table 3), which further included maternal age at delivery, gestational age, parity, and area of living as a proxy variable for iodine intake (West Denmark with moderate iodine deficiency vs East Denmark with mild iodine deficiency). The models corroborated our findings in the stratified analyses. To evaluate possible interaction between maternal intake of iodine supplements and maternal smoking, we included an interaction term (smoking $\times$ iodine supplement intake), which was not statistically significant in any of the models $(P>0.1)$.

Table 3 Predictors of serum Tg in multivariate linear regression models. Serum $\mathrm{Tg}$ and ratio $\mathrm{Tg}$ cord/maternal serum were log transformed before analysis. Results are exponentiated $\beta$ and $95 \% \mathrm{Cl}$ respectively.

\begin{tabular}{llc}
\hline Dependent variables & Explanatory variables & Multivariate $^{\mathrm{a}} \boldsymbol{\beta}(95 \% \mathrm{Cl})$ \\
\hline Maternal serum Tg & lodine supplements $^{\mathrm{b}}$ & $0.48(0.36-0.64)$ \\
& Smoking $^{\mathrm{C}}$ & $1.52(1.15-2.00)$ \\
Cord serum Tg & lodine supplements $^{\mathrm{b}}$ & $0.57(0.44-0.73)$ \\
& Smoking $^{\mathrm{C}}$ & $1.38(1.08-1.77)$ \\
Ratio Tg cord/maternal serum & lodine supplements $^{\mathrm{b}}$ & $1.16(0.85-1.57)$ \\
& Smoking $^{\mathrm{C}}$ & $0.93(0.69-1.26)$
\end{tabular}

Tg, thyroglobulin.

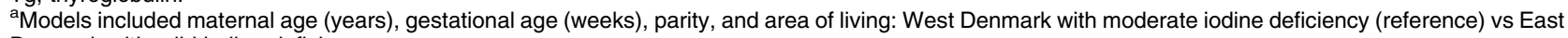
Denmark with mild iodine deficiency.

${ }^{\mathrm{b}}$ Maternal daily intake of iodine-containing supplements; yes/no (reference).

cMaternal smoking status classified from cotinine in serum and urine; smoker/nonsmoker (reference). 


\section{Discussion}

\section{Study rationale and principal findings}

Iodide autoregulation of NIS in the thyroid gland is well known (12), whereas in the lactating mammary gland, no autoregulation of NIS seems to occur (14). To evaluate autoregulation of placental iodide transport, we used $\mathrm{Tg}$ in maternal and cord serum at delivery as markers of iodine deficiency in the mother and the fetus respectively $(27,28,29)$.

Thiocyanate inhibits NIS-mediated iodide transport in cultured placental cells (11). In contrast to inhibition of NIS in the thyroid, which affects iodide uptake in both the maternal and the fetal thyroid, impaired placental iodide transport would affect the iodide supply to the fetus exclusively. We assumed that thiocyanate would inhibit NIS and possibly other transporters involved in placental iodide transport, and we hypothesized the following scenarios: if no autoregulation of iodide transport takes place in the placenta, thiocyanate from maternal smoking would lead to a particular worsening of fetal iodine deficiency with a relatively higher increase in cord serum $\mathrm{Tg}$. On the other hand, if there is autoregulation of placental iodide transport, we would observe the same degree of smoking-induced $\mathrm{Tg}$ changes in the mother and the fetus.

$\mathrm{Tg}$ was higher in cord serum than in maternal serum, which is a normal finding not related to iodine deficiency (38). $\mathrm{Tg}$ in maternal and cord serum increased to a similar degree as indicated by similar ratios between cord serum and maternal serum $\mathrm{Tg}$ in smoking and nonsmoking mothers and in accordance with the identical levels of thiocyanate in maternal and cord serum. Thus, placental iodide transport seemed unaffected in smoking mothers, suggesting autoregulation of placental iodide transport similar to autoregulation of NIS in the thyroid gland. Thyroid function was not affected by maternal smoking, neither in the mother nor in the fetus, but maternal smoking led to high serum $\mathrm{Tg}$ in both, which is consistent with autoregulation of NIS in the thyroid.

On the other hand, the data collected on day 5 postpartum were related to iodide transport in the lactating mammary gland and not in the placenta. As previously published (14), breast milk iodine content and urinary iodine in the newborns on day 5 postpartum were low if the mother was a smoker, corresponding to lack of NIS autoregulation in the lactating mammary gland.

\section{Previous studies}

Studies of placental tissue samples have demonstrated that placenta contains iodine $(4,5,6)$, and in vitro cell culture studies have suggested a functional role of NIS $(10,11)$ and SMVT $(19)$ in placental iodide transport. In addition, the chloride-iodide transporter pendrin has been proposed to play a role (11).
Autoregulation of placental NIS in iodine-deficient rats was found by Schrøder van der Elst et al. (39), and $\mathrm{Li}$ et al. (40) demonstrated in the BeWo (human trophoblast) cell line that iodide suppressed NIS expression with a decrease in iodide uptake. They suggested that iodide inhibition of NIS expression might be through inhibition of human chorionic gonadotrophin (hCG) action on NIS expression (40). Thus, our results are consistent with previous findings of similarities between the iodide autoregulation of NIS in the thyroid and in the placenta.

Unlike iodide autoregulation, NIS in the placenta and in the thyroid may be regulated differently by other mechanisms. For example, TSH enhances NIS expression in the thyroid (12) whereas hCG enhances NIS expression in the placenta (10). Also, the paired-box transcription factor PAX8 may affect thyroidal and placental NIS differently (41), and recently, a regulatory role of placental $\mathrm{O}_{2}$ concentrations on NIS expression in placenta has been investigated (42). In addition, the functional role of pendrin in iodide transport might differ between the placenta and the thyroid (7).

Another transporter present in the placenta and involved in iodide transport is the SMVT. SMVT mediates the uptake of the micronutrients pantothenate, biotin, and lipoate in placental cells (43), and in SMVT-expressing oocytes, this transport was inhibited by iodide (19). Moreover, SMVT-mediated sodiumdependent iodide transport was demonstrated. Notably, the transport was insensitive to perchlorate $\left(\mathrm{CIO}_{4}^{-}\right)$, which is a known competitive NIS inhibitor (12), but the effect of thiocyanate was not investigated (19).

Burns et al. $(5,6)$ recently reported results indicating that placenta is not only involved in transport but also stores iodine and they suggested that this storage may protect against fetal iodine deficiency. It is unknown whether maternal smoking affects placental iodine content.

\section{Strengths and limitations}

This study is to our knowledge the first study evaluating autoregulation of placental iodide transport in a clinical setting. The number of pregnant women studied in the stratified analyses was rather low, but at the time of enrollment, the frequency of smoking among pregnant women in Denmark was much higher than today (44), making it very difficult to repeat the study. Also, as the study was conducted before the mandatory iodine fortification of salt in Denmark (32), the pregnant women suffered from mild-to-moderate iodine deficiency, which makes iodide transport by NIS or other placental iodide transporters more sensitive to the competitive inhibition by thiocyanate.

Thiocyanate crosses placenta as indicated by similar serum thiocyanate levels in maternal and cord serum (14). Thus, it seems unlikely that our results would be explained by lack of thiocyanate access to placental 
iodide transporters. It has been demonstrated that thiocyanate inhibits NIS-mediated iodide transport in cultured placental cells (11) and structural similarities between NIS and SMVT exist (12); however, it cannot be excluded that placental iodide transport is primarily mediated by transporters and/or mechanisms not affected by thiocyanate. On the other hand, in vivo findings in rats (39) and in vitro findings in placental cultured cells of iodide-dependent regulation of NIS expression in the placenta (40) are consistent with our findings. Further studies are needed to clarify exact roles of different transporters in placental iodide transport.

We found higher serum Tg in smoking mothers and their newborns compared with the nonsmoking groups, but the effect of smoking was only significant in the group without maternal intake of iodine supplements. This observation is consistent with the biochemical characteristics of competitive inhibition; its effect is reduced by higher substrate concentration (45), in this case iodide.

$\mathrm{Tg}$ in maternal serum collected at the time of admission for delivery and in cord serum collected at delivery was used as a marker of iodine deficiency in mother and fetus respectively. Serum Tg was previously shown to be a sensitive marker of iodine deficiency in the general population $(28,29)$ and in pregnancy $(27)$. $\mathrm{Tg}$ is a thyroid-specific protein but is also released from the thyroid gland due to other stimuli than iodine deficiency. However, none of the participants suffered from thyroid disease.

\section{Conclusion}

In a cohort of iodine-deficient pregnant women, maternal smoking increased serum $\mathrm{Tg}$ in both mother and fetus as a sign of aggravating iodine deficiency. However, the degree of iodine deficiency varied in parallel between smoking mother and fetus with no signs of a particular worsening in the fetus. The results therefore suggest autoregulation of placental iodide transport similar to the thyroid but in contrast to the lactating mammary gland, which further substantiates that iodide transporters might display tissue-specific autoregulation and inhibitory profiles. Moreover, it may indicate that iodide transporters other than NIS, insensitive to thiocyanate inhibition, are active in the human placental iodide transport.

\section{Declaration of interest}

The authors declare that there is no conflict of interest that could be perceived as prejudicing the impartiality of the research reported.

\section{Funding}

This research did not receive any specific grant from any funding agency in the public, commercial or not-for-profit sector.

\section{Acknowledgements}

The authors gratefully acknowledge their colleagues Karl-Gerhard Børlum, Peter L Johannesen, Peter Dam, Ebbe Fuglsang, and Allan Johansen for help with recruiting participants and collecting data.

\section{References}

1 Morreale de Escobar G, Obregon MJ \& Escobar del Rey F. Role of thyroid hormone during early brain development. European Journal of Endocrinology 2004151 U25-U37. (doi:10.1530/eje. $0.151 \mathrm{U} 025)$

2 Delange F. The role of iodine in brain development. Proceedings of the Nutrition Society $2000 \mathbf{5 9}$ 75-79. (doi:10.1017/ S0029665100000094)

3 Burrow GN, Fisher DA \& Larsen PR. Maternal and fetal thyroid function. New England Journal of Medicine 1994331 1072-1078. (doi:10.1056/NEJM199410203311608)

4 Gulaboglu M, Borekci B \& Halici Z. Placental tissue iodine level and blood magnesium concentration in pre-eclamptic and normal pregnancy. International Journal of Gynaecology and Obstetrics 2007 98 100-104. (doi:10.1016/j.ijgo.2007.03.047)

5 Burns R, Azizi F, Hedayati M, Mirmiran P, O'Herlihy C \& Smyth PP. Is placental iodine content related to dietary iodine intake? Clinical Endocrinology 201175 261-264. (doi:10.1111/j.1365-2265. 2011.04039.x)

6 Burns R, O'Herlihy C \& Smyth PP. The placenta as a compensatory iodine storage organ. Thyroid 201121 541-546. (doi:10.1089/ thy.2010.0203)

7 Bidart JM, Lacroix L, Evain-Brion D, Caillou B, Lazar V, Frydman R, Bellet D, Filetti $S$ \& Schlumberger M. Expression of $\mathrm{Na}^{+} / \mathrm{I}^{-}$ symporter and Pendred syndrome genes in trophoblast cells. Journal of Clinical Endocrinology and Metabolism $2000 \mathbf{8 5}$ 4367-4372. (doi:10.1210/jc.85.11.4367)

8 Mitchell AM, Manley SW, Morris JC, Powell KA, Bergert ER \& Mortimer RH. Sodium iodide symporter (NIS) gene expression in human placenta. Placenta 200122 256-258. (doi:10.1053/plac. 2000.0609)

9 Di Cosmo C, Fanelli G, Tonacchera M, Ferrarini E, Dimida A, Agretti P, De Marco G, Vitti P, Pinchera A, Bevilacqua G et al. The sodium-iodide symporter expression in placental tissue at different gestational age: an immunohistochemical study. Clinical Endocrinology 200665 544-548. (doi:10.1111/j.1365-2265.2006. 02577.x)

10 Arturi F, Lacroix L, Presta I, Scarpelli D, Caillou B, Schlumberger M, Russo D, Bidart JM \& Filetti S. Regulation by human chorionic gonadotropin of sodium/iodide symporter gene expression in the JAr human choriocarcinoma cell line. Endocrinology 2002143 2216-2220. (doi:10.1210/en.143.6. 2216)

11 Manley SW, Li H \& Mortimer RH. The BeWo choriocarcinoma cell line as a model of iodide transport by placenta. Placenta $2005 \mathbf{2 6}$ 380-386. (doi:10.1016/j.placenta.2004.07.004)

12 Dohan O, De la Vieja A, Paroder V, Riedel C, Artani M, Reed M, Ginter CS \& Carrasco N. The sodium/iodide symporter (NIS): characterization, regulation, and medical significance. Endocrine Reviews 200324 48-77. (doi:10.1210/er.2001-0029)

13 Tazebay UH, Wapnir IL, Levy O, Dohan O, Zuckier LS, Zhao QH, Deng HF, Amenta PS, Fineberg S, Pestell RG et al. The mammary gland iodide transporter is expressed during lactation and in breast cancer. Nature Medicine 20006 871-878. (doi:10.1038/ 78630)

14 Laurberg P, Nohr SB, Pedersen KM \& Fuglsang E. Iodine nutrition in breast-fed infants is impaired by maternal smoking. Journal of Clinical Endocrinology and Metabolism $2004 \quad 89$ 181-187. (doi:10.1210/jc.2003-030829)

15 Spitzweg C, Joba W, Eisenmenger W \& Heufelder AE. Analysis of human sodium iodide symporter gene expression in extrathyroidal tissues and cloning of its complementary deoxyribonucleic acids 
from salivary gland, mammary gland, and gastric mucosa. Journal of Clinical Endocrinology and Metabolism $1998 \mathbf{8 3}$ 1746-1751. (doi:10.1210/jc.83.5.1746)

16 Nicola JP, Basquin C, Portulano C, Reyna-Neyra A, Paroder M \& Carrasco N. The $\mathrm{Na}^{+} / \mathrm{I}^{-}$symporter mediates active iodide uptake in the intestine. American Journal of Physiology. Cell Physiology 2009296 C654-C662. (doi:10.1152/ajpcell.00509.2008)

17 Prasad PD, Wang H, Huang W, Fei YJ, Leibach FH, Devoe LD \& Ganapathy V. Molecular and functional characterization of the intestinal $\mathrm{Na}^{+}$-dependent multivitamin transporter. Archives of Biochemistry and Biophysics 1999366 95-106. (doi:10.1006/ abbi.1999.1213)

18 Wang H, Huang W, Fei YJ, Xia H, Yang-Feng TL, Leibach FH, Devoe LD, Ganapathy V \& Prasad PD. Human placental $\mathrm{Na}^{+}$dependent multivitamin transporter. Cloning, functional expression, gene structure, and chromosomal localization. Journal of Biological Chemistry 1999 274 14875-14883. (doi:10.1074/jbc.274.21.14875)

19 de Carvalho FD \& Quick M. Surprising substrate versatility in SLC5A6: $\mathrm{Na}^{+}$-coupled $\mathrm{I}^{-}$transport by the human $\mathrm{Na}^{+} /$multivitamin transporter (hSMVT). Journal of Biological Chemistry 2011 286 131-137. (doi:10.1074/jbc.M110.167197)

20 Bidart JM, Mian C, Lazar V, Russo D, Filetti S, Caillou B \& Schlumberger M. Expression of pendrin and the Pendred syndrome (PDS) gene in human thyroid tissues. Journal of Clinical Endocrinology and Metabolism 200085 2028-2033. (doi:10.1210/jc.85.5.2028)

21 Tonacchera M, Pinchera A, Dimida A, Ferrarini E, Agretti P, Vitti P, Santini F, Crump K \& Gibbs J. Relative potencies and additivity of perchlorate, thiocyanate, nitrate, and iodide on the inhibition of radioactive iodide uptake by the human sodium iodide symporter. Thyroid 200414 1012-1019. (doi:10.1089/ thy.2004.14.1012)

22 Laurberg P, Pedersen IB, Carle A, Andersen S, Knudsen N \& Karmisholt J. The relationship between thiocyanate and iodine. In Comprehensive Handbook of Iodine: Nutritional, Biochemical, Pathological and Therapeutic Aspects, edn 1st, pp 275-281. Eds VR Preedy, GN Burrow \& RR Watson, Oxford: Academic Press/Elsevier, 2009.

23 Knudsen N, Bulow I, Laurberg P, Ovesen L, Perrild H \& Jorgensen T. Association of tobacco smoking with goiter in a low-iodine-intake area. Archives of Internal Medicine 2002162 439-443. (doi:10.1001/archinte.162.4.439)

24 Nohr SB, Laurberg P, Borlum KG, Pedersen KM, Johannesen PL, Damm P, Fuglsang E \& Johansen A. Iodine status in neonates in Denmark: regional variations and dependency on maternal iodine supplementation. Acta Paediatrica 199483 578-582. (doi:10.1111/j.1651-2227.1994.tb13085.x)

25 Schone F, Leiterer M, Lebzien P, Bemmann D, Spolders M \& Flachowsky G. Iodine concentration of milk in a dose-response study with dairy cows and implications for consumer iodine intake. Journal of Trace Elements in Medicine and Biology 2009 23 84-92. (doi:10.1016/j.jtemb.2009.02.004)

26 Leung AM, Braverman LE, He X, Heeren T \& Pearce EN. Breastmilk iodine concentrations following acute dietary iodine intake. Thyroid 201222 1176-1180. (doi:10.1089/thy.2012. 0294)

27 Pedersen KM, Borlum KG, Knudsen PR, Hansen ES, Johannesen PL \& Laurberg P. Urinary iodine excretion is low and serum thyroglobulin high in pregnant women in parts of Denmark. Acta Obstetricia et Gynecologica Scandinavica 1988 67 413-416. (doi:10.3109/00016348809004251)

28 Vejbjerg P, Knudsen N, Perrild H, Laurberg P, Carle A, Pedersen IB, Rasmussen LB, Ovesen L \& Jorgensen T. Thyroglobulin as a marker of iodine nutrition status in the general population. European Journal of Endocrinology 2009161 475-481. (doi:10.1530/EJE09-0262)

29 Knudsen N, Bulow I, Jorgensen T, Perrild H, Ovesen L \& Laurberg P. Serum $\mathrm{Tg}-$ a sensitive marker of thyroid abnormalities and iodine deficiency in epidemiological studies. Journal of Clinical Endocrinology and Metabolism 200186 3599-3603. (doi:10. $1210 /$ jc.86.8.3599)

30 Nohr SB, Laurberg P, Borlum KG, Pedersen KM, Johannesen PL, Damm P, Fuglsang E \& Johansen A. Iodine deficiency in pregnancy in Denmark. Regional variations and frequency of individual iodine supplementation. Acta Obstetricia et Gynecologica Scandinavica $1993 \quad 72$ 350-353. (doi:10.3109/00016349 309021111)

31 Nohr SB \& Laurberg P. Opposite variations in maternal and neonatal thyroid function induced by iodine supplementation during pregnancy. Journal of Clinical Endocrinology and Metabolism 200085 623-627. (doi:10.1210/jc.85.2.623)

32 Laurberg P, Jorgensen T, Perrild H, Ovesen L, Knudsen N, Pedersen IB, Rasmussen LB, Carle A \& Vejbjerg P. The Danish investigation on iodine intake and thyroid disease, DanThyr: status and perspectives. European Journal of Endocrinology 2006 155 219-228. (doi:10.1530/eje.1.02210)

33 Degiampietro P, Peheim E, Drew D, Graf H \& Colombo JP. Determination of thiocyanate in plasma and saliva without deproteinisation and its validation as a smoking parameter. Journal of Clinical Chemistry and Clinical Biochemistry 1987 25 711-717.

34 Laurberg P. Thyroxine and 3,5,3'-triiodothyronine content of thyroglobulin in thyroid needle aspirates in hyperthyroidism and hypothyroidism. Journal of Clinical Endocrinology and Metabolism 1987 64 969-974. (doi:10.1210/jcem-64-5-969)

35 Laurberg P \& Pedersen KM. Sensitive assay for thyroglobulin autoantibodies in serum employing polyethylene glycol for precipitation. Scandinavian Journal of Clinical and Laboratory Investigation $1988 \mathbf{4 8} 137-140$.

36 Spencer CA, Takeuchi M, Kazarosyan M, Wang CC, Guttler RB, Singer PA, Fatemi S, LoPresti JS \& Nicoloff JT. Serum thyroglobulin autoantibodies: prevalence, influence on serum thyroglobulin measurement, and prognostic significance in patients with differentiated thyroid carcinoma. Journal of Clinical Endocrinology and Metabolism $1998 \mathbf{8 3}$ 1121-1127. (doi:10.1210/jc.83. 4.1121)

37 Laurberg P, Pedersen KM, Hreidarsson A, Sigfusson N, Iversen E \& Knudsen PR. Iodine intake and the pattern of thyroid disorders: a comparative epidemiological study of thyroid abnormalities in the elderly in Iceland and in Jutland, Denmark. Journal of Clinical Endocrinology and Metabolism $1998 \mathbf{8 3}$ 765-769. (doi:10.1210/ jc.83.3.765)

38 Laurberg P, Andersen S, Bjarnadottir RI, Carle A, Hreidarsson A, Knudsen N, Ovesen L, Pedersen I \& Rasmussen L. Evaluating iodine deficiency in pregnant women and young infants complex physiology with a risk of misinterpretation. Public Health Nutrition 200710 1547-1552. (doi:10.1017/S136898000 7360898)

39 Schröder-van der Elst JP, van der Heide D, Kastelijn J, Rousset B \& Obregon MJ. The expression of the sodium/iodide symporter is up-regulated in the thyroid of fetuses of iodine-deficient rats. Endocrinology $2001 \mathbf{1 4 2} 3736-3741$. (doi:10.1210/en.142. 9.3736)

40 Li H, Richard K, McKinnon B \& Mortimer RH. Effect of iodide on human choriogonadotropin, sodium-iodide symporter expression, and iodide uptake in BeWo choriocarcinoma cells. Journal of Clinical Endocrinology and Metabolism 200792 4046-4051. (doi:10.1210/jc.2006-2358)

41 Ferretti E, Arturi F, Mattei T, Scipioni A, Tell G, Tosi E, Presta I, Morisi R, Lacroix L, Gulino A et al. Expression, regulation, and function of paired-box gene 8 in the human placenta and placental cancer cell lines. Endocrinology 2005146 4009-4015. (doi:10.1210/en.2005-0084)

$42 \mathrm{Li} \mathrm{H}$, Landers K, Patel J, Richard K \& Mortimer RH. Effect of oxygen concentrations on sodium iodide symporter expression and iodide uptake and hCG expression in human choriocarcinoma BeWo cells. American Journal of Physiology. Endocrinology and Metabolism 2011300 E1085-E1091. (doi:10.1152/ajpendo. 00679.2010) 
43 Prasad PD, Ramamoorthy S, Leibach FH \& Ganapathy V. Characterization of a sodium-dependent vitamin transporter mediating the uptake of pantothenate, biotin and lipoate in human placental choriocarcinoma cells. Placenta $1997 \mathbf{1 8}$ 527-533. (doi:10.1016/0143-4004(77)90006-6)

44 Egebjerg Jensen K, Jensen A, Nohr B \& Kruger Kjaer S. Do pregnant women still smoke? A study of smoking patterns among 261,029 primiparous women in Denmark 1997-2005. Acto Obstetricia et Gynecologica Scandinavica $2008 \quad \mathbf{8 7} \quad 760-767$. (doi:10.1080/00016340802179814)
45 Pincus MR, Abraham NZ \& Carty RP. Clinical enzymology. In Henry's Clinical Diagnosis and Management by Laboratory Methods, edn 22nd, pp 273-295. Eds RA McPherson \& MR Pincus, Philadelphia, PA, USA: Saunders/Elsevier, 2011.

Received 29 August 2012

Revised version received 26 February 2013

Accepted 26 February 2013 